\title{
Adventures in Attica - a personal view of the VIIIth World Congress of Psychiatry
}

\author{
ElSPETH GUTHRIE, Senior Registrar in Psychiatry and DAWn Black, Lecturer in \\ Psychiatry, Rawnsley Building, Manchester Royal Infirmary, Manchester M13 9WL \\ (correspondence)
}

Little did we know, as fledgling conference attenders, what lay in store for us when we learnt that our papers had been accepted for the VIIIth World Congress of Psychiatry in Athens, October 1989.

Daunted at the prospect of presenting our paltry research projects at such an august gathering, we had prepared our talks assiduously, weeks in advance.

On arrival in Athens, we rapidly discovered that things were not to be as we had anticipated.

Unfortunately, organisational skills are not a Greek strongpoint. Hence we missed most of the opening ceremony because of transport difficulties. We arrived at the Peace and Friendship Stadium in Athens just in time for the promised refreshments, only to find 8000 tired and hungry psychiatrists milling around a large concrete arena, in complete darkness, desperately scavenging for what little food was available.

We learnt later that one distinguished psychiatrist had been sufficiently enterprising to acquire some food by climbing into the back of a Greek catering van and pillaging its contents amid cheers of encouragement from bystanders. Clearly, possessing such initiative and tenacity is an essential prerequisite for any aspiring professor of psychiatry in the Thatcher era.

Returning to the hotel was far from straightforward. After driving for an hour and a half, our congress coach driver revealed that he was lost. Fortunately, an intrepid American psychiatric colleague with an interest in orienteering, who had only arrived in Athens a few hours earlier, was able to save the day and guide the bewildered driver to our hotel. Exhausted and still hungry, we retired to bed, with instructions from the conference organisers that the only bus to the conference the following day would be leaving at 7 a.m.!

Having awoken at 9.30 a.m. and enjoyed a leisurely breakfast, prospects brightened when the first of a stream of luxurious pharmaceutical company coaches arrived to round up the many stragglers and convey them to the conference centre.

Attempting to register was not without its difficulties. Hundreds of delegates from the UK and the USA jostled at a single desk, while business was far from brisk at the desks for Zaire and Lebanon.
Without doubt, the highlight of the conference for most participants was the discovery of a free umbrella at the bottom of the plush conference bags. Needless to say, the profile of the pharmaceutical industry was high, but we were surprised to see eminent psychiatrists elbowing each other out of the way to enter a raffle to win a free fountain pen!

Lacking such competitive skills, we retired to the quiet of Jimmy's Bar, a small restaurant within the stadium complex. We thought a light snack would help to fortify us for the celebrity lecture by Kitty Dukakis. We learnt, however, that Jimmy's Bar is a unique establishment, where after one hour of trying to order a drink, the waiter may show it to you, out not actually allow you to drink it. We wondered whether this was some Greek custom with which we were unfamiliar. As time passed, we looked on enviously as Lundbeck sponsored delegates tucked into a sumptuous repast. Luckily, they soon left and, by this point we had become so desperate that we stole the few morsels that remained on their table. Survival was taking precedence over etiquette and intellectual stimulation.

Having missed Mrs Dukakis' presentation, our attempts to attend other sessions of interest were foiled by the complex geography of the stadium. Although maps of the centre abounded, there were no arrows to indicate one's location. Dizzy, after many circumnavigations of the building, we finally reeled into the session of our choice.

We rapidly learnt that the diversity in the standard of research presentations was enormous. After the first day, the only people who appeared to attend most of the smaller sessions were the speakers themselves, plus one or two "buddies" to provide moral support. Fortunately, our own presentations, to a small but presumably select audience, many of whom did not speak English, passed off without incident.

We are unable to comment on the rest of the scientific programme from personal experience, although we noted that the Greek president of the WPA had co-authored 22 of the papers at the congress, demonstrating wide ranging research interests from neuroimaging to dynamic psychotherapy!

Unable to afford the exorbitant price of the conference gala dinner at the Hilton Hotel, we 
were taken by a Greek friend to a modest taverna in the Plaka district where we enjoyed a lively atmosphere and fine cuisine. But it seems our more prosperous colleagues were less fortunate, as, despite their sumptuous surroundings, the food rations were, once again, meagre. We were told that the seating arrangements were of such an intimate nature that it rendered the transfer of food from plate to mouth almost impossible. As we were entertained by an excellent bouzouki band, our colleagues at the Hilton were treated to a rendition of Eurovision pop contest song favourites.

Despite the variability of the scientific programme, and some of the difficulties we have touched upon, we enjoyed our first foray into the international conference scene immensely. We particularly valued the opportunity of meeting so many interesting people from other countries around the world, and talking informally about their research interests.

However, we quickly learnt from our more experienced colleagues that to admit one is enjoying oneself is to reveal a shameful lack of sophistication. The correct code of conduct at all such occasions is to disparage everything and bemoan one's cruel fate at being obliged to attend so many international gatherings.

Since we have not yet mastered this art, we are eagerly looking forward to the IXth World Congress in Rio.

\section{COMPETITION! COMPETITION! COMPETITION!}

\section{Christmas Limerick Competition}

In lighter vein, the Bulletin is setting a Limerick Competition with a psychiatric flavour - open to all Fellows, Members, Inceptors, and Affiliates of the College, who may, of course, be helped by their next of kin.

The competition is to complete a limerick beginning with one of the following first lines:

"There was a disciple of Freud ...."

"I've been to the Maudsley she cried ....."

"There once was an MRCPsych ....."
Three prizes of books will be awarded for the wittiest and most original entries, and the competition will be judged by a small panel of eminent Professors in Psychiatry.

We are hoping to publish the best entries, so could you please err on the side of respectability!

Entries should be sent to: Dr Adrian Yonace, Consultant Psychiatrist, St Ann's Hospital, Haven Road, Canford Cliffs, Poole BH13 7LN, to arrive by Christmas Eve.

Good Luck! 